REVIEW ARTICLE

\title{
How to Increase Resilience of Healthy Newborns in Underdeveloped Countries?
}

\author{
Asim Kurjak ${ }^{1}$, Milan Stanojevic ${ }^{2}$
}

\begin{abstract}
Out of eight Millennium Development Goals (MDGs) derived from the Millennium Declaration, three (goals IV, V, and VI) were health related. High infant, under-five, and maternal mortality rates decreased in developing countries, but the rate was not satisfactory, because the preset targets were not achieved by 2015. The aim of this paper is to discuss whether the problems of neonatal health could be solved by the same approach as for the implementation of the MDGs or the paradigm should be changed. It is proposed to use Antonovsky's concept of salutogenesis, which is health oriented, meaning that it cares about conditions and mechanisms contributing to preserving health, opposing to pathogenesis aiming to investigate the pathogenesis of the disease with the semiology, symptoms, syndromes, and concepts of systemic, iatrogenic, or endogenous causes of disease. Besides that it is important to increase the resilience of mothers and neonates, understood as "the capacity, processes, or outcomes of successful adaptation in the context of significant threats to function or development." Implementing Baby Friendly Hospital Initiative of the World Health Organization and UNICEF in developing countries can preserve health of healthy mothers and healthy newborn infants by increasing their resilience.
\end{abstract}

Keywords: Infant health, Maternal health, Millennium Development Goals, Resilience, Salutogenesis.

Donald School Journal of Ultrasound in Obstetrics and Gynecology (2020): 10.5005/jp-journals-10009-1619

\section{INTRODUCTION}

Poverty, disease, hunger, environmental degradation, and discrimination against women were the reasons why the Millennium Declaration has been signed by United Nations (UN) in September 2000. ' Out of eight Millennium Development Goals (MDGs) derived from the declaration, three (goals IV, V, and VI) were health related. High infant, under-five, and maternal mortality rates decreased in developing countries, but the rate was not satisfactory, because the preset targets were not achieved by 2015. That was the reason for the UN to launch 17 Sustainable Development Goals (SDGs), covering all aspects of human life in developed and developing countries, carried forward the matters not solved by MDGs. Sustainable Development Goals should be implemented till 2030. ${ }^{2}$

The aim of this paper is to discuss whether the problems of neonatal health could be solved by the same approach as for the implementation of the MDGs or the paradigm should be changed.

\section{Concepts of Salutogenesis and Resilience}

The paradigm of health and disease has been changing from $1970 \mathrm{~s}$ when Antonovsky introduced the new concept of salutogenesis. 3,4 This concept is health oriented, meaning that it cares about conditions and mechanisms contributing to preserving health, opposing to pathogenesis aiming to investigate the pathogenesis of the disease with the semiology, symptoms, syndromes, and concepts of systemic, iatrogenic, or endogenous causes of disease. ${ }^{5}$ According to Antonovsky, each society develops its own hypothesis on which to build clinical and experimental practices in health and disease. ${ }^{4}$ Antonovsky also described "generalized resistance resources" (GRR) that can support well-being in any circumstances (good or bad), dividing GRR to internal resources (such as knowledge and attitudes) and external ones (such as social support and ease of access to services). The same author introduced the sense of

\begin{abstract}
1,2Department of Obstetrics and Gynecology, Medical School University of Zagreb, Clinical Hospital Sveti Duh, Zagreb, Croatia

Corresponding Author: Asim Kurjak, Department of Obstetrics and Gynecology, Medical School University of Zagreb, Clinical Hospital Sveti Duh, Zagreb, Croatia, Phone: +385 1 4684349, e-mail: asim. kurjak@public.carnet.hr

How to cite this article: Kurjak A, Stanojevic M. How to Increase Resilience of Healthy Newborns in Underdeveloped Countries? Donald School J Ultrasound Obstet Gynecol 2020;14(1):28-31.

Source of support: Nil

Conflict of interest: None
\end{abstract}

coherence (SOC) as the measure of internal and external resources to maintain and improve health, describing four components of the SOC as comprehensible (perceived clarity, order, and structure), manageable (easily find resources for coping), and meaningful (has purpose). ${ }^{4}$ This theory explores health systematically along the health continuum, excluding dichotomy of being in a state of health or being in a state of disease. ${ }^{6}$

The concept of GRR is similar to the concept of resilience, which was by Masten defined as "the capacity of a dynamic system to withstand or recover from significant challenges that threaten its stability, viability, or development". ${ }^{7}$ Masten et al. also pointed out that resilience can be understood as "the capacity, processes, or outcomes of successful adaptation in the context of significant threats to function or development". ${ }^{8}$ In other words, Lutha and Cicchetti considered resilience as a "dynamic process wherein individuals display positive adaptation despite experiences of significant adversity or trauma". ${ }^{9}$ The main similarity of those two concepts is that they use intrinsic capacity of the individual and the environment to preserve the health. They are not technology oriented and they are manageable, meaningful, and comprehensible. ${ }^{10}$ 


\section{Salutogenesis and Resilience in Maternal Health}

Most of the pregnant women and their babies are healthy, and the main task of perinatal care is to maintain or even enhance this healthy state. ${ }^{10}$ In recent research and follow-up of the pregnancy and neonatal outcome, the indicators of morbidity and mortality are focused on the risk and adverse outcomes, meaning that maternity care evaluation is pathogenically oriented, similar to indicators used for surveillance of state of illness. ${ }^{10}$ In the care for healthy mothers and their children, it seems very important to find the ways how to maintain health and well-being, having in mind the concepts of salutogenesis and resilience. ${ }^{10}$ This approach includes provision of care minimizing medicalization and iatrogenic intervention, with the promotion and enhancement of positive state of health. ${ }^{10}$ Even research of maternity intrapartum care as well as clinical care is focused mostly on the indicators and managements preventing adverse health outcomes, rather than on activities preserving well-being and health (salutogenesis). ${ }^{6}$ In the systematic reviews of randomized trials of intrapartum interventions with salutogenically focused outcome defined as one reflecting positive health and well-being rather than illness or adverse even prevention or avoidance. ${ }^{6}$ Out of the 436,102 systematic reviews were selected out of which 16 presented salutogenically focused outcome while in 49 the outcome was salutogenically nonfocused. ${ }^{6}$ Sixteen salutogenically focused outcome categories (representing 135 individual-reported outcomes across all reviews) were identified in the 102 reviews $^{6}$ (Table 1). ${ }^{6}$

Table 1: Unique list of salutogenically focused reported outcomes from systematic reviews, known as salutogenic intrapartum core outcome set ${ }^{6}$

\begin{tabular}{ll}
\hline $\begin{array}{l}\text { Salutogenically focused outcome } \\
\text { categories }\end{array}$ & $\begin{array}{l}\text { Number of times individual } \\
\text { outcome was reported }\end{array}$ \\
\hline $\begin{array}{l}\text { Maternal satisfaction with care, } \\
\text { experience, etc. }\end{array}$ & 51 \\
$\begin{array}{l}\text { Breastfeeding* (e.g., initiation, duration, } \\
\text { and success) }\end{array}$ & 32 \\
$\begin{array}{l}\text { Control* (perceived/personal control) } \\
\text { Spontaneous vaginal birth (or "normal }\end{array}$ & 12 \\
vaginal birth") & 6 \\
$\begin{array}{l}\text { Positive relationship with infant/ } \\
\text { bonding }\end{array}$ & 6 \\
$\begin{array}{l}\text { Well-being (mother/father, } \\
\text { psychological/emotional) }\end{array}$ & 5 \\
$\begin{array}{l}\text { Caregiver experience/satisfaction* } \\
\text { Views* (mother's and/or father's) }\end{array}$ & 5 \\
Mobility during labor & 4 \\
Pregnancy prolongation & 3 \\
Spontaneous rupture of membranes & 2 \\
Comfort & 2 \\
Maternal perception of pain & 2 \\
experienced* & 1 \\
Maternal parenting confidence & 1 \\
Relaxation & \\
Intact perineum & \\
\hline
\end{tabular}

*Positive reference
In the investigated systematic reviews, there was a little consideration of maternal and neonatal positive health or wellbeing outcomes. ${ }^{6}$ If women, who can easily find resources for coping with stressful situations and had positive views of birth and birth experience, had negative experience during birth, will undergo salutogenic birth anyway. ${ }^{6}$ As the authors of the paper pointed out, incorporating salutogenically focused outcome measures in maternity care will enable health-oriented maternity care, rather than from the illness-oriented maternity care with the indicators, such as morbidity and mortality. This kind of approach will enable to motivate patients to actively participate in the preservation of their health and health of their newborn babies. ${ }^{6}$

\section{EXAMPLE OF THE IMPLEMENTATION OF Salutogenic Theory in Practice (Norwegian "New Mothers" Program)}

In the study from Norway, the theory of salutogenesis was tested in the "New Mothers" program in which public health nurses (PHN) delivered child early intervention program within the child healthcare service (CHS) by establishing a trusting relationship with family at an early stage of pregnancy. ${ }^{11}$ The intention and hope is that the PHN can serve and support the family throughout late pregnancy and until the child turns 2 years of age. During the first years, the most rapid and developmentally significant changes occur in child's life, which is the reason to detect and prevent the risk factors and promote health. ${ }^{11}$ By assessing child's and family's needs and strengths, supporting families through early interventions, negative outcomes can be prevented and positive development promoted. ${ }^{11}$ Public health nurses wanted to use the theory of salutogenesis, saying that people who viewed their life positively can better manage stressful situations and were better able to improve their health. ${ }^{11}$ Every person has some SOC, and not all individuals have the same ability to use them. The intervention should be based on emphasizing strengths and resilience, not potential deficits. ${ }^{11}$ So, the PHN were conscious of the importance of supporting families, and they were aware that focus on parental strengths is very important. ${ }^{11}$ The universal approach would be supported by incorporating a salutogenic theory, emphasizing resistance and strengths, not potential deficits. ${ }^{11}$ Their intervention was to meet the family during home visits, which were enabling individual approach and adjustable perspective on family strengths and resilience. ${ }^{11}$ The most important interventions were Motivational Interviewing and Empathetic Communication during the home visit. ${ }^{11}$ Home visits were making families to be more in control and became as setting for contact, trust, and observation. ${ }^{11}$

At the end, it was concluded that application of the salutogenic theory enabled change in the health paradigm by moving from the measurements of pathology to identification of what generates and maintains health in the natural environment of families - their homes. It is of utmost importance to help the families stay healthy by supporting their well-being and increasing the mothers SOC, self-efficacy, and motivation to keep the family healthy.

\section{Can Salutogenic Theory be Applied in Developed Countries?}

Theory of salutogenesis is universal and can be applied in any situation regardless of the existing resources and situation. Although it was not used very often in maternal and child health, 
it is worth trying to implement the theory in the developing countries with limited resources for the protection of mothers and children. To implement the theory, it is needed to investigate the situation in the low-resource setting for delivering mother-infant care and define the salutogenically focused reported outcomes to build SIPCOS. ${ }^{6}$ After that, the most important questions are how to increase resilience and preserve health of newborn babies who are mostly dying due to preterm birth, infections, and birth complications. By very cheap investments, such as preventing infections, making available basic parenteral antibiotics and local disinfectants for umbilical stump, prenatal corticosteroids, and availability of the basic resuscitation equipment can save hundred thousands of neonatal lives in 1 year. By improving skilled birth attendant (a doctor, nurse, or midwife), coverage from $52 \%$ in sub-Saharan Africa and Southern Asia to $71 \%$ as in the world or to $100 \%$ as in the developed countries would save many maternal and neonatal lives. ${ }^{2}$ By teaching skilled health attendants to implement new World Health Organization and UNICEF Baby Friendly Hospital Initiative to strengthen breastfeeding would have short-term and long-term benefits on maternal and infant health and breastfeeding rates $^{12-14}$ (Table 2 ).

The most important procedures supportive to breastfeeding are skin-to-skin contact (SSC) between healthy mother and healthy newborn and keeping them together since birth (so-called rooming-in). ${ }^{12,15}$ The evidence supports using immediate or early SSC between healthy newborn and healthy mother to promote breastfeeding and helps the newborns to stay healthy. It is still not known whether early SSC for healthy infants helps them make the transition to the outside world more smoothly after birth. The evidence supports that early SSC should be normal practice for

Table 2: Ten steps to successful breastfeeding (WHO and UNICEF) ${ }^{12}$

\section{Critical management procedures}

1a. Comply fully with the International Code of Marketing of Breast-milk Substitutes and relevant World Health Assembly resolutions.

1b. Have a written infant feeding policy that is routinely communicated to staff and parents.

1c. Establish ongoing monitoring and data-management systems.

2. Ensure that staff have sufficient knowledge, competence, and skills to support breastfeeding.

Key clinical practices

3. Discuss the importance and management of breastfeeding with pregnant women and their families.

4. Facilitate immediate and uninterrupted skin-to-skin contact and support mothers to initiate breastfeeding as soon as possible after birth.

5. Support mothers to initiate and maintain breastfeeding and manage common difficulties.

6. Do not provide breastfed newborns any food or fluids other than breast milk, unless medically indicated.

7. Enable mothers and their infants to remain together and to practice rooming in 24 hours a day.

8. Support mothers to recognize and respond to their infants' cues for feeding.

9. Counsel mothers on the use and risks of feeding bottles, teats, and pacifiers.

10. Coordinate discharge so that parents and their infants have timely access to ongoing support and care. healthy newborns including those born by cesarean and babies born prematurely at 35 weeks or more. ${ }^{15}$

It is crucial not to separate the mother and the newborn infant after birth. In comparison to separate care infants, the rooming-in infants were $92 \%$ more likely to be exclusively breastfed on day 4 postpartum before hospital discharge (relative ratio $1.92,95 \%$ confidence interval [1.34-2.76], $p=0.00038 ; 153$ participants). ${ }^{16}$

\section{Conclusion}

It is crucial to change the attitude of healthcare providers and policymakers toward heath and disease from pathogenetic to salutogenic approach, which means to show the mothers and the babies how to preserve health by increasing their resilience. Such an approach depends on intrinsic and extrinsic GRR and on the definition of salutogenic core outcome indicators. Simple intervention can help in preserving health and decreasing the prevalence of adverse outcomes in mothers and their newborn babies particularly in developing countries.

\section{References}

1. World Health Organization. Millennium Development Goals. https:// www.who.int/en/news-room/fact-sheets/detail/millenniumdevelopment-goals-(mdgs) (Accessed January 2, 2020).

2. United Nations. Millennium Development Goals Report, 2015. United Nations: New York, 2015. https://www.un.org/millenniumgoals/2015_ MDG_Report/pdf/MDG\%202015\%20rev\%20(July\%201).pdf (Accessed Jan 04, 2020).

3. Antonovsky A. Unraveling the Mystery of Health. San Francisco: Jossey-Bass; 1987.

4. Antonovsky A. The structure and properties of the sense of coherence scale. Soc Sci Med 1993;36(6):725-733.

5. d'Alessio PA. Salutogenesis and beyond. Dermatol Ther 2019;32(1):e12783. DOI: 10.1111/dth.12783.

6. Smith V, Daly D, Lundgren I, et al. Protocol for the development of a salutogenic intrapartum core outcome set (SIPCOS). BMC Med Res Methodol 2017;17(1):61. DOI: 10.1186/s12874-017-0341-5.

7. Masten AS. Resilience in children threatened by extreme adversity: framework for research, practice, and translational synergy. Dev Psychopathol 2011;23:493-506. DOI: 10.1017/S0954579411000198.

8. Masten AS, Best KM, Garmezy N. Resilience and development: contributions from the study of children who overcome adversity. Dev Psychopathol 1990;2(4):425-444. DOI: 10.1017/S0954579400005812.

9. Lutha SS, Cicchetti D. The construct of resilience: implications for interventions and social policies. Dev Psychopathol 2000;12(4): 857-885. DOI: 10.1017/s0954579400004156.

10. Perez-Botella M, Downe $S$, Magistretti $C M$, et al. The use of salutogenesis theory in empirical studies of maternity care for healthy mothers and babies. Sex Reprod Healthc 2015;6(1):33-39. DOI: 10.1016/j.srhc.2014.09.001.

11. Leirbakk MJ, Torper J, Engebretsen E, et al. Formative research in the development of a salutogenic early intervention home visiting program integrated in public child health service in a multiethnic population in Norway. BMC Health Serv Res 2018;18(1):741. DOI: 10.1186/s12913-018-3544-5.

12. World Health Organization, UNICEF. Protecting, promoting, and supporting breastfeeding in facilities providing maternity and newborn services: the revised Baby-friendly Hospital Initiative 2018. Implementation guidance. World Health Organization: Geneva, 2018. https://www.who.int/nutrition/publications/infantfeeding/ bfhi-implementation/en/ (Accessed January 9, 2020).

13. Pérez-Escamilla R, Martinez JL, Segura-Pérez S. Impact of the baby-friendly hospital initiative on breastfeeding and child health outcomes: a systematic review. Matern Child Nutr 2016;12:402-417. DOI: 10.1111/mcn.12294. 
14. Balogun OO, O'Sullivan EJ, McFadden A, et al. Interventions for promoting the initiation of breastfeeding. Cochrane Database Syst Rev 2016;11(11):CD001688. DOI: 10.1002/14651858.CD001688. pub3.

15. Moore ER, Bergman N, Anderson GC, et al. Early skin-to-skin contact for mothers and their healthy newborn infants. Cochrane Database
Syst Rev 2016;11:CD003519. DOI: 10.1002/14651858.CD003519. pub4.

16. Jaafar $\mathrm{SH}, \mathrm{Ho} \mathrm{JJ}$, Lee KS. Rooming-in for new mother and infant versus separate care for increasing the duration of breastfeeding. Cochrane Database Syst Rev 2016;8:CD006641. DOI: 10.1002/14651858. CD006641.pub3. 